\title{
A Study on the Gender Recognition and Job Satisfaction of Female Physical Education Teachers
}

\author{
Seungman Lee ${ }^{1}$ and Hohyun Song ${ }^{2}$ \\ ${ }^{1}$ Global Cyber University, Korea \\ ${ }^{2}$ Korea National University of Education, Korea \\ ${ }^{1}$ lsm14pe@gmail.com, ${ }^{2}$ hohyunss@nate.com
}

\begin{abstract}
The goal of this study is to empirically examine how gender stereotypes, role conflict, job burnout, and job satisfaction are related among female physical education teachers. For this purpose, we surveyed 320 female physical education teachers in Korea from September to October 2019. First, gender stereotypes had a positive effect on role conflict. Second, gender stereotypes had no effect on job burnout. Third, gender stereotypes had no effect on job satisfaction. Fourth, role conflict had a positive effect on job burnout. Fifth, role conflict had no effect on job satisfaction. Finally, sixth, job burnout had a negative effect on job satisfaction. Based on these results, we were able to identify the difficulties faced by female physical education teachers, who are pressured to take on masculine images and roles, and that these factors were detrimental to their passion for teaching and job satisfaction. As such, we emphasized some of the occupational difficulties faced by female physical education teachers and presented the need to address these issues.
\end{abstract}

Keywords: Female physical education teachers, Gender stereotypes, Role conflict, Job burnout, Job satisfaction

\section{Introduction}

In step with the recent trends toward the realization of gender equality in society, the participation of women has become pronounced in sports, which has previously been considered a masculine area. In particular, there has been a rising trend in the number of women among PE teachers - a job in which the majority had previously been men. Schools are perceived as feminine spaces. In contrast, considering the characteristics of PE as a course that is perceived as being male-centered, the various gender issues encountered by female PE teachers are expected to present greater complexities compared to what would be the case in most other occupations. In addition to the social perceptions by which PE teachers are viewed, there is also a structural male bias in terms of institutions and facilities. Despite this, many female PE teachers currently working at schools have shown a passion for teaching and expertise in leading classes on par with their male counterparts. In view of the importance of job satisfaction within schools, neglecting to look into the processes linking gender stereotypes, role conflict, and job burnout will significantly hamper the efforts to derive workable implications regarding gender issues within the teaching profession, which in turn would be linked to the actual job satisfaction. Thus, it is necessary to conduct an empirical

Article history:

Received (October 21, 2019), Review Result (December 5, 2019), Accepted (January 26, 2020) 
study that comprehensively analyzes the links between gender stereotypes, role conflict, job burnout, and job satisfaction using a single model. The purpose of this study is to specify and estimate a structural model regarding gender stereotypes and role conflict, job burnout, and job satisfaction among female PE teachers, thereby providing a theoretical basis for improving the work environments of female PE teachers and boosting their job satisfaction. To these ends, we introduced the following research hypotheses: (1) gender stereotypes will have a positive effect on role conflict (2) gender stereotypes will have a positive effect on job burnout (3) gender stereotypes will have a negative effect on job satisfaction (4) role conflict will have a positive effect on job burnout (5) role conflict will have a negative effect on job satisfaction (6) job burnout will have a negative effect on job satisfaction.

\section{Research methods}

\subsection{Participants}

This study used convenience sampling, a non-probability sampling method which samples subjects who can be accessed at a time and place convenient to the researchers. To achieve its goal, this study was divided into a preliminary survey and a main survey. The preliminary survey examined 110 female PE teachers living in Korea, while the main survey examined 451 female PE teachers living in Korea. [Table 1] shows the specific distribution of the participants.

Table 1. General characteristics of study subjects

\begin{tabular}{|c|c|c|c|c|c|}
\hline \multirow{2}{*}{ Variable } & \multirow{2}{*}{ Value } & \multicolumn{2}{|c|}{ Pilot survey } & \multicolumn{2}{|c|}{ Main survey } \\
\hline & & Freq (persons) & Percent $(\%)$ & Freq (persons) & Percent $(\%)$ \\
\hline \multirow{4}{*}{ Age } & $20 \mathrm{~s}$ & 15 & 13.6 & 28 & 13.4 \\
\hline & $30 \mathrm{~s}$ & 31 & 28.2 & 79 & 37.6 \\
\hline & $40 \mathrm{~s}$ & 42 & 38.2 & 78 & 37.1 \\
\hline & $50 \mathrm{~s}$ & 22 & 20.0 & 25 & 11.9 \\
\hline \multirow{2}{*}{ Marital status } & No & 36 & 32.7 & 82 & 39.0 \\
\hline & Yes & 74 & 67.3 & 128 & 61.0 \\
\hline \multirow{3}{*}{$\begin{array}{c}\text { Years of } \\
\text { experience }\end{array}$} & 10 years or less & 41 & 37.3 & 64 & 30.5 \\
\hline & $11-20$ years & 45 & 40.9 & 99 & 47.1 \\
\hline & 21 years or more & 24 & 21.8 & 47 & 22.4 \\
\hline \multirow{3}{*}{$\begin{array}{c}\text { Educational } \\
\text { degree }\end{array}$} & Bachelors & 49 & 44.5 & 112 & 53.3 \\
\hline & Masters & 53 & 48.2 & 81 & 38.6 \\
\hline & Doctoral & 8 & 7.3 & 17 & 8.1 \\
\hline \multirow{4}{*}{$\begin{array}{c}\text { Years of } \\
\text { athletic } \\
\text { experience }\end{array}$} & None & 78 & 70.9 & 166 & 79.0 \\
\hline & Less than 5 years & 15 & 13.6 & 21 & 10.0 \\
\hline & 5-10 years & 11 & 10.0 & 13 & 6.2 \\
\hline & 10 years or more & 6 & 5.5 & 10 & 4.8 \\
\hline \multicolumn{2}{|r|}{ Total } & 110 & 100 & 210 & 100 \\
\hline
\end{tabular}

\subsection{Measurement tools}

The questionnaire survey method was used for data collection. The survey questions were drawn, based on their relevance for the purposes of this study, from instruments whose 
validity and reliability have been established through prior studies. The survey was administered as follows: The researcher made prior contact with female PE teachers, gave detailed descriptions regarding the intentions of the study, and obtained their approval. Then, female PE teachers were instructed to respond to an online survey using the self-administered method. The questionnaire covered 5 topics: the general characteristics of respondents, gender stereotypes, role conflict, job burnout, and job satisfaction. Information on the general characteristics of the respondents was collected using 5 questions covering age, educational degree, years of experience, marital status, and years of athletic experience. These questions were measured in nominal scale. The gender stereotype scale, comprising 33 items, was developed by [1] and applied by [2]. The role conflict scale used was developed by [3] and comprises 37 items. The job burnout scale used was a modified version [4] of the Maslach Burnout Inventory (MBI) introduced by [5], comprising 22 items. The job satisfaction scale used in this study was the Teacher Job Satisfaction Questionnaire (TJSQ) developed by [6] and applied by [7][8]. The scores of items for gender stereotypes, role conflict, job burnout, and job satisfaction were measured from "very much so" (5) to "not at all" (1), with each score calculated independently.

\subsection{Reliability test}

The present study used Cronbach's $\alpha$ to test for the internal reliability of items in the questionnaire. Cronbach's $\alpha$ ranges from 0 to 1 , and it is considered reliable in normal cases when $\alpha$ is .8 or higher [9]. Accordingly, items were removed when their $\alpha$ was less than .8 , or when the overall Cronbach's $\alpha$ without the item was higher than it was with the item. Based on the above, this study removed one social-values item and one physical-values item.

\subsection{Validity test}

For the purpose of establishing the reliability of the measurement instruments constructed, SPSS 18.0 was used to estimate internal consistency based on Cronbach's $\alpha$. To verify validity, the AMOS 18.0 package was used to conduct CFA, deriving convergent validity and discriminant validity. The reliability analysis found that the Cronbach's $\alpha$ of the sub-variables ranged from .783 to .864. As all variables had Cronbach's $\alpha$ values exceeding .7, internal consistency was found to be established. In particular, as none of the items were found to cause the loss of validity ("alpha if item deleted"), all items were included in the study. Next, convergent and discriminant validity were examined via CFA. With respect to the goodness of fit, we looked at incremental fit indices such as NFI, IFI, CFI, and absolute fit indices such as $\chi 2 / \mathrm{DF}$, RMSEA, GFI, and RMR. The fit indices of the CFA of the proposed model were largely found not to meet the criteria. As such, we repeatedly applied the process of first discarding the modification indices with high cross loadings, then additionally discarding items based on the SMC value. While some fit indices of the resulting modified model did not meet the criteria, we considered the recommendation regarding freedom from sample characteristics, such that CFI(>.9) and RMSEA(<.08) [2]. With a CFI value of .947 and an RMSEA value of .077 , the model's fit indices may be considered admissible. Next, using the CFA results reported in Table 3, we evaluated the convergent and discriminant validity. First, convergent validity was gauged via the standardized regression coefficient values and the construct reliability values. The standardized regression coefficients ranged between .436 and .964 and the construct reliability values ranged between .979 and .992 , indicating that convergent validity had been secured. Next, discriminant validity was assessed by comparing 
the correlations among each of the variables and their AVE (average variance extracted). We found that as the squared correlation coefficient (.527) between the most strongly correlated variables, "role conflict" and "job burnout," was smaller than the AVE of role conflict (.981) and job burnout (.977), discriminant validity had been established.

\subsection{Data processing method}

To conduct inference on the structural model of the gender stereotypes, role conflict, job burnout, and job satisfaction among female PE teachers, data on 320 such teachers (110 persons from the pilot survey, 210 persons from the main survey) were used to run a frequency analysis and a reliability analysis using SPSS 18.0. Using the AMOS 18.0 package, we conducted CFA prior to conducting path analysis. The procedures followed for the analysis of structural equation models generally run from (1) development of theoretical model, (2) estimating the model using actual data, (3) model evaluation, (4) modification of model as needed, and (5) model re-evaluation [9]. These were the steps followed in this study.

\section{Results}

\subsection{Descriptive statistics analysis}

[Table 2] summarizes the results of the descriptive statistics (mean, standard deviation, skewness, kurtosis) of the variables included in this study's analysis. The means ranged between 1.61 and 3.77 while the standard deviations ranged between .44 and .84 . Next, we looked at skewness and kurtosis, suitable values of which would allow us to assume normality in the structural equation model. Specifically, skewness looks at whether the data are distributed symmetrically such that normality is retained, while kurtosis gauges whether most of the score ratios are concentrated along the center or the tails of the normal distribution curve. The criteria for univariate normality call for skewness $< \pm 3.0$ [11] and kurtosis $< \pm 10.0$ [12]. For our data, the absolute value of skewness ranged between .07 and .89 and the absolute value of kurtosis ranged between .03 and .62 . These findings indicate that our data satisfy the normality assumption, such that the estimation of the unknown parameters via maximum likelihood would not be affected. Thus, we found that our data met the criteria for structural equation model analysis [11].

Table 2. Descriptive statistics

\begin{tabular}{|c|c|c|c|c|c|}
\hline \multirow{4}{*}{ Variable } & Sub-variable & Mean & S.E. & Skewness & Kurtosis \\
\hline \multirow{4}{*}{$\begin{array}{c}\text { Gender } \\
\text { stereotypes }\end{array}$} & Societal stereotypes & 2.37 & .79 & .26 & -.52 \\
\cline { 2 - 6 } & Occupational stereotypes & 2.58 & .74 & .13 & .03 \\
\cline { 2 - 6 } & External stereotypes & 3.28 & .84 & -.44 & -.18 \\
\cline { 2 - 6 } & Psychological stereotypes & 3.38 & .66 & -.35 & .47 \\
\cline { 2 - 6 } & Intellectual stereotypes & 2.05 & .62 & .34 & -.36 \\
\cline { 2 - 6 } & Mean & 2.73 & .52 & -.13 & -.03 \\
\hline \multirow{4}{*}{ Role confusion } & Role ambiguity & 1.90 & .75 & .73 & .22 \\
\cline { 2 - 6 } & Lack of ability & 1.70 & .73 & .89 & .27 \\
\cline { 2 - 6 } & Environmental obstacles & 1.61 & .60 & .75 & .35 \\
\cline { 2 - 6 } & Lack of cooperation & 1.77 & .70 & .71 & .20 \\
\hline
\end{tabular}




\begin{tabular}{|c|c|c|c|c|c|}
\hline & Mean & 1.75 & .63 & .71 & .09 \\
\hline \multirow{4}{*}{ Job burnout } & Emotional exhaustion & 1.76 & .63 & .49 & -.14 \\
\cline { 2 - 6 } & Personal accomplishment & 2.04 & .77 & .42 & -.58 \\
\cline { 2 - 6 } & Depersonalization & 2.12 & .80 & .30 & -.62 \\
\cline { 2 - 6 } & Mean & 1.98 & .67 & .38 & -.37 \\
\hline \multirow{3}{*}{ Job satisfaction } & Development prospects & 3.44 & .47 & -.28 & .43 \\
\cline { 2 - 6 } & Practicality & 3.77 & .61 & -.49 & -.07 \\
\cline { 2 - 6 } & Professional consciousness & 3.47 & .46 & .07 & -.07 \\
\cline { 2 - 6 } & Mean & 3.56 & .44 & -.22 & .33 \\
\hline
\end{tabular}

\subsection{Analysis of model fit}

The study model includes 4 latent variables - gender stereotypes, role conflict, job burnout, job satisfaction - and 15 observed variables. As there is no consensus regarding which fit indices are best suited for evaluating the goodness of fit of structural equation models, there is a need to report as many indices as possible and to use these for model evaluation. Of these, RMSEA has the strongest advantages and should be used along with FNI and CFI [10]. As such, in this study we assessed the incremental fit indices such as NFI, IFI, and CFI and the absolute fit indices such as $\chi^{2} / \mathrm{DF}, \mathrm{RMSEA}, \mathrm{GFI}$, and RMR. The fit indices of the overall model used for hypothesis testing are summarized in Table 2, indicating that some indices did not meet the criteria. Thus, residual covariances were used for two observed variables with high modification indices (MI). As the resultant modified model had all fit indices within the acceptable range, it was used for conducting the final analysis.

Table 3. Goodness of fit of the proposed model

\begin{tabular}{|c|c|c|c|c|c|c|c|c|}
\hline Model & $\chi 2 / \mathrm{DF}$ & RMR & GFI & NFI & IFI & TLI & CFI & RMSEA \\
\hline Proposed model & 2.224 & .030 & .887 & .908 & .947 & .933 & .947 & .077 \\
\hline Modified model & 1.720 & .029 & .912 & .930 & .969 & .961 & .969 & .059 \\
\hline
\end{tabular}

\subsection{Path analysis}

The magnitudes and test results of the direct effects in the final model are as detailed in Table 3. First, looking at how gender stereotypes affected role conflict, the path coefficient was $.160(t=1.975)$ and was found to be positive at the current significance level. Second, the path coefficient from gender stereotypes to job burnout was .044(t=1.026) and was found to have no effect at the current significance level. Third, the path coefficient from gender stereotypes to job satisfaction equaled $-.135(\mathrm{t}=-1.741)$ and was found to have no negative effect at the current significance level. Fourth, the path coefficient from role conflict to job burnout was $.898(\mathrm{t}=11.196)$ and was significantly positive, indicating that role conflict had a positive effect. Fifth, the path coefficient from role conflict to job satisfaction was equal to $.148(t=.707)$ and was found to have no effect at the current significance level. Sixth, the path coefficient from job burnout to job satisfaction was -.645(t=-2.996) and was found to be significantly negative at the current significance level. 
Table 3. Parameter estimates from research model

\begin{tabular}{|c|c|c|c|c|c|c|c|c|}
\hline Hypothesis & \multicolumn{3}{|c|}{ Path } & Estimate & S.E. & C.R. & $p$ & Decision \\
\hline 1 & Stereotypes & $\rightarrow$ & Role conflict & .160 & .105 & 1.975 & $.048^{*}$ & Accepted \\
\hline 2 & Stereotypes & $\rightarrow$ & Job burnout & .044 & .061 & 1.026 & .305 & Rejected \\
\hline 3 & Stereotypes & $\rightarrow$ & $\begin{array}{c}\text { Job } \\
\text { satisfaction }\end{array}$ & -.135 & .062 & -1.741 & .082 & Rejected \\
\hline 4 & Role conflict & $\rightarrow$ & Job burnout & .898 & .086 & 11.196 & $.000^{* * *}$ & Accepted \\
\hline 5 & Role conflict & $\rightarrow$ & $\begin{array}{c}\text { Job } \\
\text { satisfaction }\end{array}$ & .148 & .129 & .707 & .480 & Rejected \\
\hline 6 & Job burnout & $\rightarrow$ & $\begin{array}{c}\text { Job } \\
\text { satisfaction }\end{array}$ & -.645 & .124 & -2.996 & $.003^{* *}$ & Accepted \\
\hline$* * * p<.001, * * p<.01, * p<.05$ & \multicolumn{7}{|c|}{} \\
\hline
\end{tabular}

\section{Discussion \& conclusions}

The objective of this study was to examine the relations between gender stereotypes, role conflict, job burnout, and job satisfaction among female PE teachers. For this purpose, a survey was conducted in the pilot and main phases. Analyzing the survey results, we derived the following findings: First, gender stereotypes had a positive effect on role conflict. Second, gender stereotypes had no effect on job burnout. Third, gender stereotypes had no effect on job satisfaction. Fourth, role conflict had a positive effect on job burnout. Fifth, role conflict had no effect on job satisfaction. Sixth, job burnout had a negative effect on job satisfaction. The imbalance in the gender ratio of teachers has emerged as a social issue in Korea. Under such circumstances, some have expressed concern that more women have entered traditionally male fields such as PE. However, contemporary society aims for a social structure and culture of gender equality, founded on scientific and rational reasoning. Therefore, in view of the fact that PE and sports activities contribute to the harmonious development and nurturing of both body and mind, sports have come to be perceived as a fundamentally important human activity rather than the exclusive purview of males. This has led to a greater necessity for women's participation in sports [5]. Furthermore, considering the various efforts that are being made within schools for the balanced development of androgyny, there is a need to do away with the dichotomous conceptions of masculinity and femininity in PE classes as well. Gender equality involves more than introducing new ways to define and reflect masculinity and femininity. However, gender equality will not be complete so long as gender ideology and sports remain unchanged. Therefore, change will be facilitated if the prejudices pervading school organizations and the subject of PE are discarded, so that the gender stereotypes and role conflicts of female PE teachers are resolved. The conclusion derived in this study from the above findings is as follows: Among female PE teachers, gender stereotypes lead to role conflict, which in turn gives rise to job dissatisfaction via job burnout. Thus, improvements to work environments are needed to help female PE teachers avoid the difficulties arising from gender stereotypes and to alleviate role conflict. Additionally, there would be a need to consider various means for resolving the perception of certain fields as being masculine, as well as to boost the job satisfaction of female PE teachers.

\section{References}

[1] Kim D. I., "A Study on the relationship between gender stereotypes and authoritarianism," Research Institute of Korean Culture, vol.63, no.2-3, pp.45-58, (1993) 
[2] An G. L., Choo N. Y., and Cho S. H., "Effects of role ambiguity and role conflict for physical education teachers on job satisfaction and job performance," The Korea Contents Society, vol.10, no.11, 476-484, (2010)

[3] Kim M. S., and Park S. Y., "Development of a Role Conflict Scale for Clinical Nurses," Journal of Korean Academy of Nursing, vol.25, no.4, pp.741-750, (1995)

[4] Lee, J. H., "The analysis of effects between job-satisfaction, burnout and perceived teacher's emotional intelligence in early childhood teaching," The Korean Journal of Child Education, vol.16, no.4, pp.199-210, (2007)

[5] Lim, B. J., "Introduction in Sociology of Sport," Seoul: Donghwa Press, (2010)

[6] Maslach C., and Jackson S. E. "Maslach burnout inventory manual (2nd ed.). Palo Alto," CA: Consulting Psychologist Press, (1986)

[7] Kim M. H., and Yang H. J., "A study on the job satisfaction and job stress according to a type of welfare facilities among their staffs," Journal of community welfare, vol.23, pp.259-282, (2011)

[8] Song Kyeng-my and Cho Sung-je, "The effect of trainee counseling psychologists' self-efficacy on interpersonal relations," International Journal of Social Welfare Promotion and Management, vol.6, no.3, pp.13-18, (2019) DOI:10.21742/IJSWPM.2019.6.3.03

[9] Sung, T. J., “Simple stat using SPSS/AMOS,” Seoul: HakJisa Press, (2014)

[10] Hong S. H., "The criteria for selecting appropriate fit indices in structural equation modeling and their rationales," Korean Journal of Clinical Psychology, vol.19, no.1, pp.161-177, (2000)

[11] West. S. G., Finch J. F., and Curran P. J., "Structural equation model with non-normal variables: Problems and remedies," In R. Hoyle (Ed.), Structural Equation Modeling: Concepts, Issues and Applications. Newbury Park, CA: Sage., (1995)

[12] Kline, R. B., "Principles and practice of structural equation modeling (3nd ed.)," New York: Guilford, (2011)

\section{Author}

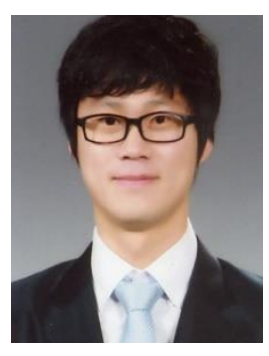

\section{Seungman Lee}

- $\mathrm{PhD}$ in education

- GeumHo High School (P.E.) Teacher

- Global Cyber University adjunct professor

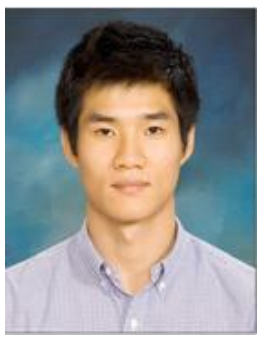

Hohyun Song

- $\mathrm{PhD}$ in education

- Joenju Hosung Middle School School (P.E.) Teacher

- Korea National University of Education adjunct professor 
A Study on the Gender Recognition and Job Satisfaction of Female Physical Education Teachers

This page is empty by intention. 